\title{
Erratum to: Foreword
}

\section{Michael Dopita}

Received: 25 November 2009 / Accepted: 25 November 2009 / Published online: 24 December 2009

(C) Springer Science+Business Media B.V. 2009

Erratum to: Astrophys Space Sci (2009) 324: 77

DOI 10.1007/s10509-009-0157-9

The link to the website should read:

http://www.iaa.es/ eperez/cluster/cluster07.html

The online version of the original article can be found under doi:10.1007/s10509-009-0157-9.

M. Dopita $(\bowtie)$

The Australian National University, Cotter Road, Weston Creek

ACT 2611, Australia

e-mail: Michael.Dopita@anu.edu.au 